-

\title{
Homecare Service Providers as an Organizational Form of Support for the Elderly: Establishment and Planning of Optimal Capacity
}

\author{
Polona ŠPRAJC, Iztok PODBREGAR, Alenka BREZAVŠČEK
}

\begin{abstract}
University of Maribor, Faculty of Organizational Sciences, Kidriceva cesta 55a, 4000 Kranj, Slovenia polona.sprajc@fov.uni-mb.si, iztok.podbregar@fov.uni-mb.si, alenka.brezavscek@fov.uni-mb.si
\end{abstract}

\begin{abstract}
Background and Purpose: Different studies have highlighted health care allocation problems in Slovenia that indicate the increased need for homecare services for the elderly. It was also found that Slovenian municipalities differ dramatically in the availability of elder care services. A number of older people with diverse unmet needs for care remains. Therefore, the need for the establishment of an additional type of formal homecare services for the elderly exists.

Design/Methodology/Approach: Although many positive effects of home elder care against institutional care are stressed in the literature, the results of many studies performed in recent years have indicated that accessibility of homecare for elderly in Slovenia remains scarce, and it is not equally accessible throughout the country. To mitigate this problem, a new organizational form called "elder homecare service provider" is indicated. The aim of the provider is to offer a variety of different services for the elderly (e.g. homemaking, social networking, transfer services, basic life needs, basic health services, etc.). The establishment of such an organization needs to be designed carefuly, while the unique characteristics and specific needs of the target population must be addressed to optimize desired outcomes.

Results: The aim of the paper is to provide fundamental guidelines for the establishment of elder homecare service provider. All essential characteristics of such an organization are defined. To ensure an appropriate level of service quality, the primarly focus is oriented towards the planning of personnel team capacity. For this purpose, the service provider was described using the stochastic queueing model, which enables service capacity optimization considering different performance measures. The usefulness of the model was illustrated with a numerical example, which has shown that the results obtained provide valuable information for decision support.

Conclusion: The establishment of a homecare service provider network would have many positive effects on society in general. The quality of the everyday life of the elderly is expected to be improved considerably, particularly in the rural areas where a lack of institutional care support is reported. Guidelines proposed in the paper together with the quantitave model for planning of its optimal capacity provide useful information, which are especially relevant in the preliminary phase of the establishment of service providers.
\end{abstract}

Keywords: elderly; service provider; performance measures; capacity planning; cost optimization; queueing theory

\section{Introduction}

Population ageing is characterized by a rise in the share of the elderly population, resulting from longer life expectancy and declining fertility rates. On average, across
OECD countries, the share of the population aged over 65 has increased from less than $9 \%$ in 1960 to $15 \%$ in 2010 and is expected to nearly double in the next four decades to reach $27 \%$ in 2050 (OECD, 2013). Moreover, the proportion of individuals aged 80 and more is expected to almost 
triple, from 4\% in 2004 to $11.4 \%$ in 2050 (OECD, 2013). Eurostat data also indicate that in $201126.6 \%$ of the population aged between 65 and 74 as well as $35.4 \%$ of the population aged 75 and over reported strong limitations in activities of daily living, while about $6.7 \%$ of them are reported to receive long-term care (LTC) (EU-SILC survey as cited in Hlebec et al., 2016a).

Since population ageing has significant effects on European societies, the problem of elder care has attracted many authors. For example, in the ENEPRI ${ }^{1}$ report, the organization and provision of LTC for the elderly population in 21 Member States of the European Union was investigated (Riedel and Kraus, 2011). In their study, Bolin et al. (2008) analysed whether informal care, ${ }^{2}$ provided by family members, and formal care ${ }^{3}$ are substitutes or complements, and whether this relationship differs across Europe. The authors determined that informal and formal homecare are substitutes, while informal care is a complement to doctor and hospital visits. Furthermore, Gannon and Davin (2010) studied the use of formal and informal care services among older people in Ireland and France. Their results highlighted some health care allocation problems which indicate the increased need of homecare services for dependent elderly people. Several studies have also proved that health-care costs rise as the proportion of elderly increase (see e.g. Rechel et al., 2009).

Results of the studies performed in Slovenia show that the situation is quite similar as in other parts of Europe. The main available LTC services in Slovenia can be divided into institutional care, homecare, and social services (Prevolnik Rupel et al., 2010). Results of the case study Genet et al. (2013) revealed that institutional care was more prevalent among Slovenes than homecare was. The reason lies in the accessibility of homecare, which was scarce (only $1.7 \%$ of people $65+$ received social homecare in 2009), it covered only 20 hours per week, and it was not equally accessible throughout the country. However, due to population ageing, the demand for LTC is growing and cannot be met by providers of formal services. Therefore, the need for performing informal services is increasing. The results of the recent study by Hlebec et al. (2016b) showed that the role of home elder care has enlarged. The authors have proclaimed informal care to be the most wide-spread form of care for the older people in Slovenia. In contrast, another study by Hlebec et al. (2016a) revealed that, despite the efforts toward care for dependent elder- ly in Slovenia, there are still a proportion of older people with several needs for care, which are being unmet. Furthermore, the research by Hlebec et al. (2014) showed that municipalities in Slovenia differ dramatically in the availability of care for the older people. Some offer only a poor quality of care (mainly smaller rural municipalities), while others provide higher quality of care and a strong combination of both institutional and homecare.

Since the capacities of formal institutions providing elder care services are limited, the Slovenian strategy of LTC from 2010 is oriented towards homecare while institutional care should be provided only in the case when the care is so demanding or costly that the provision of it at home is impossible. Such orientation has human, moral, and economic advantages. Prevolnik Rupel et al. (2010) reported that living at home strongly impacts the quality of life and the success of care, as well as its costs, which are lower in a case of cooperation of family and friends of the elderly. The authors also stress many benefits of home elder care (formal or informal) against institutional care. For example, the study of Bolin et al. (2008) has shown that informal homecare reduces the risk of depression in the elderly and that formal homecare increases their general mental health. Therefore, this is probably one of the main reasons why many older people prefer to grow old in the privacy of their homes rather than in an institution like a home for the elderly (Riedel \& Kraus, 2011).

According to the statements listed above, we can conclude that in Slovenia exists a considerable need for the establishment of a new type of formal organization providing homecare services adjusted especially for elderly people. In this context, we present the concept of elderly homecare service provider, which can offer a variety of different services (e.g. homemaking, social networking, transfer services, basic life needs, basic health services, etc.) at the homes of the elderly. Such an organization would be especially worthwhile in the rural areas, where the support of institutional care is often insufficient.

The institute of formal home-healthcare services is not something entirely new in Slovenia. One of the most frequently used approaches is "home nursing" which is organized as an independent organizational unit within primary health care institutions. The provider of home nursing care is a nurse, who is employed within the primary health care institution, where all the services provided are $100 \%$ paid for by the Health Insurance Institute of Slovenia (Prevol-

1 European Network of Economic Policy Research Institutes

2 The "textbook" definition of informal care is "a nonmarket composite commodity consisting of heterogeneous parts produced by one or more members of the social environment of the care recipient as a result of the care demands of the care recipient." Simply put, informal care is unpaid care provided by family, friends, and volunteers based on a complex social relationship between the carer and the supported person (IFA, 2014)).

3 Formal care refers to paid care services by a healthcare institution or individual for a person in need. Formal care is available in most countries privately and publicly although public formal care is significantly more limited than private options. It is widely recognized that formal care is often a last case resort which is only chosen by family members or friends who can no longer provide the necessary care to their loved one (IFA, 2014). 
nik Rupel et al., 2010). Since the empirical results (Prevolnik Rupel et al., 2010) proved that home nursing is well-accepted among the elderly population (the number of persons aged 60 and over who need home nursing care is increasing), the idea is to establish a service provider who would offer wider assortment of services, but the services would be strictly oriented to the elderly population who still live in their homes. In our opinion, such a new approach can result in many positive effects on society as a whole. In addition to the already mentioned positive effects on quality of everyday life, such institutions can also relieve the burden on institutional facilities such as homes for elderly or nursing homes and hospitals (Hlebec, 2014). Moreover, the elderly homecare service provider can aid the busy family members who must take care to their older relatives. Finally, such solutions represent an excellent opportunity for youth employment, either in the form of business marketing opportunities, public-private partnerships or social entrepreneurship.

Although some experiences in providing formal home-healthcare services exist, the establishment of an elderly homecare service provider requires an elaborate approach. Such an organization needs to be designed carefuly, and the unique characteristics and specific needs of the target population must be addressed in order to optimize desired outcomes. The aim of this paper is to provide fundamental guidelines for the establishment an elderly homecare service provider. All key organizational characteristics which have to be taken into account before a new service is launched on the market are defined. To ensure an appropriate level of service quality, the focus is oriented towards the planning of personnel team capacities. For this purpose, we developed a model based on a queuing theory approach, and illustrate its usefulness with a numerical example. The model enables the calculation of different performance measures of the elderly homecare service provider, such as traffic intensity, the probability that a customer who enters the service provider cannot be served immediately but must wait for the service, expected number of waiting customers, expected waiting time, etc. Such measures are worthwhile especially in the preliminary phase of a service provider establishment, and represent useful information for decision making to ensure an appropriate level of service quality under minimal operating costs.

Results of a literature review about homecare, provided by Basher et al. (2012), indicated that the majority of the literature work in this area is about assignment and routing problems, while the issues like resource dimensioning, homecare modelling, and districting problems are less frequently treated. From a methodological point of view, our contribution attempts to fill this gap by modelling an elderly homecare service provider with a stochastic queuing model.

The paper is organized as follows: in the second sec- tion, we have examined theoretical aspects of main organizational characteristics of an elderly homecare service provider. These characteristics must be considered in the preliminary phase of the establishment of an elderly homecare service provider. Furthermore, we provide a stochastic queuing model for the planning of optimal capacity of the personnel team. The model enables the calculation of various performance measures that provide valuable information for decision support as well as cost optimization. The usefulness of the model is illustrated with a numerical example. Finally, the main conclusions are discussed, and the directions for future research are indicated.

\section{Organizational characteristics of the elderly homecare service provider}

Successfully introducing new products or services into the market is vital to the long-term growth of a company (Kotler, \& Keller, 2006). Before a new service is launched, providers create programs to maximize the chance of success. This is often a challenging managerial decision because, in order to set the appropriate pricing levels as well as advertising and promotion budgets, providers must have reliable estimates for to respond to different levels of organizational characteristics (Luan, \& Sudhir, 2010). The distinctive nature of service performances requires strategic elements, such as service elements, price, promotion, and people (Lovelock, \& Wright, 2002, Ambler, 2003; Farris et al. 2010; Lehmann, \& Reibstein, 2006). Kajonius (2016) for example defines the social service structure as all factors affecting the conditions of caregiving, such as budget resources, staff training, reward systems, payment methods, facilities, and equipment.

Services are generally associated with the everyday needs and desires of people. A service is an act or performance offered by one party to another (Lovelock, \& Wright, 2002). Several studies to assess perceived service quality have been performed in the healthcare industry. Some have been done regarding public healthcare (Aagja, \& Garg, 2010, Camilleri, \& O'Callaghan, 1998) while others address private healthcare (Camilleri, \& O'Callaghan, 1998). The fact is that specific needs emerge daily and are associated with basic necessities of life. In contrast, there are also occasional needs that do not need to be satisfied daily. Most importantly, the range of services must be taken as understanding the needs and desires of elderly people. The expanded range can follow in consensus and according to the agreement with the individual.

Any service or product manufacturing is inevitably linked to the cost component. Price and other user outlays cover the expenditures of money, time, and effort that customers incur in purchasing and consuming services (Lovelock, \& Wright, 2002). The LTC expenses are divided 
into public and private expenditures, and expenditures for health and social LTC. Almost $80 \%$ of all expenditures for long-term social and health care are public expenditures (Prevolnik Rupel et al., 2010). In defining the pricing policy of the elderly homecare service provider, we are faced with price differentiation, which requires a more sophisticated analysis of defining service prices given the degree of scarcity of financial resources. We argue that service is not simply a market-based approach to provide services in the direction of profits, but is accompanied with a wider social responsibility, we steer toward the consistency of setting cost carriers to the interests of local communities or states. For such services, either a public-private partnership or the preparation of subsidies for vulnerable groups is considered.

Communication is both a competence that all service providers must master and an opportunity to bring out a word about them to the right place. Communication through promotion and education means all communication activities and incentives designed to build customer preference for a specific service or service provider (Lovelock, \& Wright, 2010). Because television is the most accessible technology for elderly, it can be an important technological device to serve this population segment, through features such as distance helping, support of services that promote social interaction on collective viewing, provision of medical information, or information dissemination about public services (Telmo et al., 2016). The basic promotional web is associated with the selection of a suitable location (the market, shopping centres, spas, hospitals, hotels for elderly people) and with all the tools that the marketing communication provides: advertising (e.g. web portals such as med.over.net, 24ur.com, siol.net, newsletters of pensioners' organizations, advertisements in local newspapers, etc.), sales promotion (e.g. by preparing favourable offers for certain seasonal chores), direct marketing (e.g. through catalogues that are sent to the personal address of potential users), personal sales (e.g. the establishment of personal communication and presentation of the services), and public relations (e.g. with an independent advertisement about the service provider in the already mentioned advertising media). Equally important are the tangible elements of the communication, such as a recognizable logo of the service provider, car equipment, uniforms, etc. Several studies indicate that Internet and telecommunication technologies and infrastructures may contribute significantly to the performance of health care systems (Smits, \& Janssen, 2008; Babulak, 2006). The existence of a network of health care, social care, and professional service providers, working articulately with an underlying effective management and intermediation service, based on an electronic marketplace for health and social care services, can be a powerful tool and result in effective and efficient service to people with special needs and to the population in general (Cruz-Cunha et al., 2012).
Employees involved in service production are a distinctive element within the organization (Lovelock, \& Wright, 2010). The key elements of professionalism and personal qualities assessment of service providers are clearly competences. In the context of providing services to the elderly, we assume that the main competences are linked to communication skills, social sensitivity, work versatility, integrity, ethics, and morals, flexibility, language literacy, body language, computer literacy, and ingenuity. There is a multitude of human resource practices that have been shown to have a positive correlation with business performance (Kesti, 2012). The status and role of human resource managers in the field of strategic management are closely related to its importance for human resources in terms of success and competitiveness of the organization. With the growing importance of intangible assets for the organization, the impact of strategic human resource management arises. This factor determines the significance of the human resource role in the organization. This fact reflects the human capital theory, according to which the costs associated with the procedures and processes in human resources should be viewed as an investment that will generate income in the future (Becker et al. 2001).

\section{Planning of service provider capacity}

The performance of any healthcare system is measured by its capacity and waiting cost optimization. In general, the healthcare system works as a queuing system in which patients (i.e. customers) arrive, wait for services, obtain service, and then depart. Potential disparity between customers' demand for a service and the system capacity available to meet that demand usually results in delays, which leads to higher cost of system operation and consequently to the dissatisfaction of customers. To improve the effectiveness of such a system a queueing theory approach (Beichelt, 2006; Hudoklin Božič, 2003) can be applied, and provide useful information to enhance decision making. The comprehensive overview of contributions and applications of queueing theory in the field of healthcare is provided by Fomundam, \& Herrmann (2007) or Singh (2006).

Considering an elderly homecare service provider, we can ascertain that the situation is quite similar to that of other healthcare or social systems. The primary objective of an elderly homecare service provider (in the following text "service provider") management is to organize activities in such way to ensure an appropriate level of service quality while the operating costs remain manageable. This raises questions such as:

- What is the maximal number of customers (i.e. elderly individuals) that the personnel team of the service provider is able to serve if we want to ensure that the offered services will satisfy the acceptable quality 
level (i.e. response times and consequently waiting times are not too long; fraction of customers who cannot be served immediately and need to wait for the service is not too high, etc.)?

- What is the minimal service capacity (i.e. expense of the personnel team, number of servers) if the service provider wants to supply an elderly population of a given size?

- What level of service capacity should be offered to ensure the total costs of the service provider operation are minimal?

In the next section, we present a stochastic queueing model whose application to a real situation can provide precise answers to similar questions. The usefulness of the model is illustrated by a hypothetical numerical example.

\subsection{Model assumptions}

We based our model on the following assumptions:

- the customers' requests to the service provider arrive according to a Poisson process with rate $\alpha$,

- the service provider personnel team employ $r$ workers (i.e. servers) who fulfil the customers' requests,

- the service times of any server are independent exponentially distributed random variables with parameter $1 / \sigma$,

- the service rate is independent of the queue length; servers do not go faster because the line is longer,

- the population of customers of the service provider is limited to $k$ customers; there are no other limits to the number of the queue,

- the customer who enter the service provider earlier is served earlier (i.e. FIFO discipline); there are no priority classifications for any arrival.

Considering these assumptions, the service provider can be described by the queueing model of type " $\mathrm{M} / \mathrm{M} / \mathrm{r}$ - finite number of customers” (Hudoklin Božič, 2003).

\subsection{Service provider performance measures}

Applying the queuing theory approach the following quantitative characteristics (i.e. performance measures) of the service provider can be calculated:

Traffic intensity: $\rho=\frac{\alpha}{r \sigma}$

The value $\rho$ is usually called a utilization factor, and represents a fraction of time the servers are busy.
Probability that there are exactly $i$ customers at the service provider (i.e. in the system), $i=1 . . k$ :

$$
\begin{aligned}
& p_{i}=\frac{1}{S} \frac{k !(r \rho)^{i}}{(k-1) ! i !}, \quad 0 \leq i \leq r \\
& p_{i}=\frac{1}{S} \frac{r^{r} k ! \rho^{i}}{r !(k-i) !}, \quad r \leq i \leq k
\end{aligned}
$$

The value $i$ includes the customers currently being served, as well as the customers in the queue who wait for the service.

Probability that a customer who enter the service provider cannot be served immediately, but has to wait for the service:

$$
p_{\grave{e}}=\sum_{i=r}^{k} p_{i}=1-\sum_{i=0}^{r-1} p_{i}
$$

Since $p_{\dot{e}}$ represent the fraction of customers, who cannot be served immediately, $1-p_{\grave{e}}$ is the fraction of customers who can be served immediately, without waiting.

Expected number of customers at the service provider (i.e. in the system ${ }^{4}$ ):

$E(N)=\sum_{i=0}^{k} i p_{i}$

Expected number of waiting customers (i.e. the length of the queue):

$E\left(N_{q}\right)=\sum_{i=r}^{k}(i-r) p_{i}$

Expected waiting time (i.e. time a customer spends in the queue before service begins):

$E\left(W_{q}\right)=\frac{E\left(N_{q}\right)\left(\frac{1}{\alpha}+\frac{1}{\sigma}\right)}{k-E\left(N_{q}\right)}$

Expected total waiting time (i.e. total time a customer spends at the service provider, including service and waiting time):

4 Number of customers in the system includes the customers being served as well as the customers waiting for the service. 


$$
E(W)=E\left(W_{q}\right)+\frac{1}{\sigma}
$$

The symbol $S$ in equations (2), (3) and (4) denotes the sum, which can be calculated as follows:

$$
S=\sum_{j=0}^{r-1} \frac{k !(r \rho)^{j}}{(k-j) ! j !}+\sum_{j=r}^{k} \frac{r^{r} k ! \rho^{j}}{r !(k-j) !}
$$

The measures (2) to (8) can be used as optimization criteria in defining the desired or acceptable level of service quality. The optimization criteria can be defined as follows:

- probability of a certain number of customers at the service provider should not exceed a predetermined value,

- fraction of customers who cannot be served immediately should not exceed a predetermined value,

- expected number of customers at the service provider or the expected number of waiting customers should not exceed a predetermined value,

- expected total waiting time or expected waiting time in the queue should not exceed a predetermined value.

Using iteration, we can always determine maximal number $k$ of customers or minimal number $r$ of servers to fulfil the chosen optimization criterion that ensures effective operation of the service provider.

\subsection{Cost optimization}

The goal of cost optimization is to determine such a service level which minimizes the total costs of service provider operation (see Figure 1). It can be seen from Figure 1 that the total costs of service provider operation consist of the service costs and the waiting costs.

The expected total costs of service provider operation $E(T C)$ per time unit can therefore be calculated as the sum of the expected service costs $E(S C)$ per time unit and the expected waiting costs $E(W C)$ per time unit:

$$
E(T C)=E(S C)+E(W C)=r C_{s}+E\left(N_{q}\right) C_{w}
$$

where $C_{S}$ represents the cost per time unit of each server, while $C_{W}$ denotes the opportunity cost per time unit of waiting by customers. Using iteration, we can always determine the number of servers $r$, which ensures the minimal value of $E(T C)$.

\subsection{Numerical example}

The usefulness of our model will be demonstrated with a hypothetical example. Since all the data, used in the example were adopted from the actual case studies of Smolej et al. (2008) as cited in Prevolnik Rupel et al. (2010) and Genet et al. (2013), we think that these results are sufficient to prove the applicability of the model.

Consider a service provider with a personnel team of three employees. We assume that on average one customer per hour calls or visits the service provider, and the expected service time is 30 minutes. We want to answer the following questions:

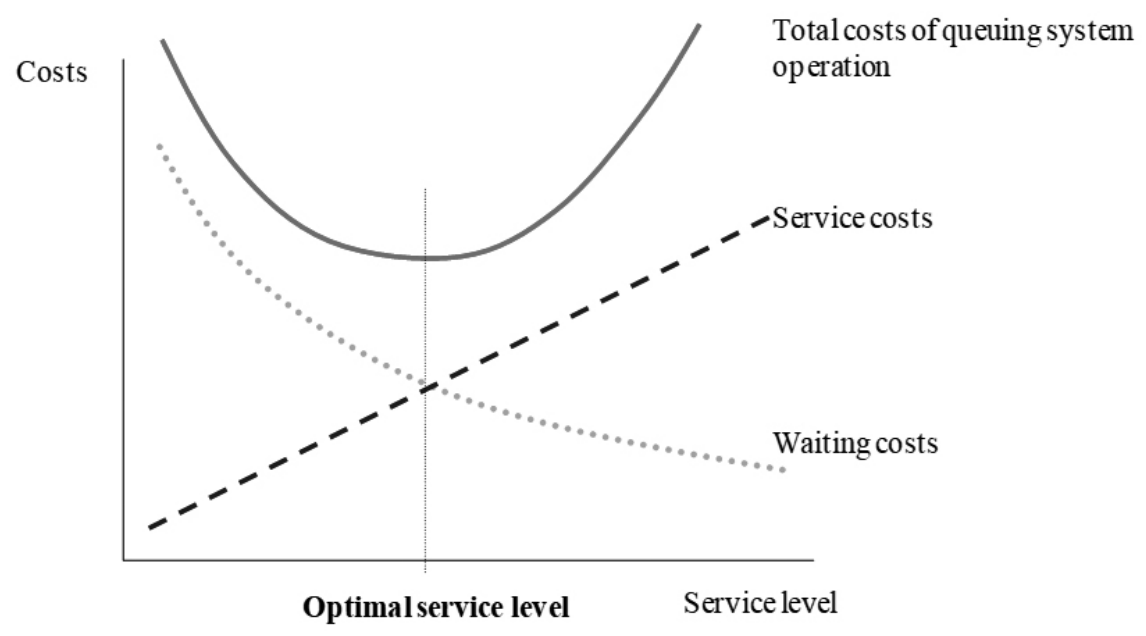

Figure 1: Costs of queueing system operation (Brezavšček, \& Baggia, 2014) 
The service provider supplies 15 customers. What are the performance measures of the system?

Considering $\alpha=1 / h, \sigma=2 / h, r=3$ and $k=15$, and using the equations (1) - (9) we calculate:

Traffic intensity: $\rho=0,167$

Fraction of customers who cannot be served immediately and need to wait to be served:

$p_{\grave{E}}=1-\left(p_{0}+p_{1}+p_{2}\right)=0.994=99.4 \%$

Expected number of customers at the service provider:

$$
E(N)=9.02
$$

Expected number of waiting customers:

$E\left(N_{q}\right)=6.03$

Expected total waiting time:

$$
E(W)=1.51 h=90.6 \min
$$

Expected waiting time in the queue:

$$
E\left(W_{q}\right)=1.01 h=60.6 \mathrm{~min}
$$

The results show that under given circumstances the service provider does not ensure the acceptable level of service quality. Almost all the customers have to wait for the service, while the expected waiting time is quite long (more than 1 hour). To prevent the dissatisfaction of customers, such a system needs improvements.

How will the performance measures change if the service provider employs another worker?

We repeat the calculation considerin $\alpha=1 / h, \sigma=2 / h$, $k=15$ and $r=4$. We obtain:

Traffic intensity: $\rho=0.125$

Fraction of customers who cannot be served immediately and need to wait to be served:

$$
p_{\grave{E}}=1-\left(p_{0}+p_{1}+p_{2}+p_{3}\right)=0.919=91.9 \%
$$

Expected number of customers at the service provider:

$$
E(N)=7.24
$$

Expected number of waiting customers:

$$
E\left(N_{q}\right)=3.36
$$

Expected total waiting time:

$$
E(W)=0.93 h=55.8 \min
$$

Expected waiting time in the queue:

$$
E\left(W_{q}\right)=0.43 h=25.8 \mathrm{~min}
$$

It is evident that employment of additional staff results in considerable improvement of all the measures of the service provider. However, we are not sure whether we achieved an optimal level of service that meets the needs of customers and, with that, contributed to their satisfaction. We can further deepen the analysis and adapt the operation of the provider to specific and pre-set requirements.

What is the maximal number of customers can the personnel team of four workers supply if we want to ensure that at least $15 \%$ of customers entering the service provider will be served immediately, meaning that at most $85 \%$ of them need to wait to be served?

Mathematical formulation of the optimization criterion can be written as follows: $p_{\check{c}} \leq 0.85$. Taking into account that $\alpha=1 / h, \sigma=2 / h$ and $r=4$ we select the initial value of $k$, and according the equations (4), (2), (3) and (9) calculate the characteristics of the service provider under consideration. Using iteration, we then determine the maximal value of $k$ to fulfil the stated optimization criterion. The results are:

$k=12 \Rightarrow p_{\check{c}}=0.721 \Rightarrow$ The optimization criterion is fulfilled, $k$ can be increased.

$k=13 \Rightarrow p_{\check{c}}=0.805 \Rightarrow$ The optimization criterion is fulfilled, $k$ can be increased.

$k=14 \Rightarrow p_{\check{c}}=0.87 \Rightarrow$ The optimization criterion is not fulfilled, 14 customers are too many.

From the obtained results, we can conclude that if we want to fulfil the stated optimization criterion (at least $15 \%$ of customers of the service provider should be served immediately; at most $85 \%$ of them needs to wait to be served), the service provider with four employees can supply at most 13 customers.

Suppose that the number of customers suddenly increases from 15 to 20 . What is the minimal number of employees needed to ensure that the expected waiting time will not exceed 20 minutes?

The optimization criterion can be written as: $E(W q) \leq 20$ $\min =0.33 h$.

Taking into account that $\alpha=1 / h, \sigma=2 / h$ and $k=20$ we select the initial value of $r$, and according the equations (8) and (9) calculate the characteristics of the service provider under consideration. Using iteration, we then determine the minimal value of $r$ to fulfil the stated optimization criterion. The results are: 
$r=6 \Rightarrow E\left(W_{q}\right)=0.25 h=15 \mathrm{~min}$

The optimization criterion is fulfilled, $r$ can be decreased.

$r=5 \Rightarrow E\left(W_{q}\right)=0,523 h=31.38$ min

The optimization criterion is fulfilled, $r$ can be decreased.

$r=4 \Rightarrow E\left(W_{q}\right)=1 h=60 \mathrm{~min}$

The optimization criterion is not fulfilled, 4 servers are not enough.

If we want to fulfil the optimization criterion (i.e. the service provider who supply 20 customers should ensure that the expected waiting time will not exceed 20 minutes), the personnel team should employ at least five workers.

Suppose that $C_{5}=€ / \mathrm{h} 6.50$ and $C_{w}=€ / h 4,30$. How many employees should the service provider who supplies 15 customers employ if we want to ensure that the expected total costs of provider operation per time unit are minimal?

Considering $\alpha=1 / h, \sigma=2 / h$ and $k=15$, and using the equation (6) we can determine the value $r$ which ensures the minimum of the cost function (10). Results are given in
Table 1 and Figure 2. It can be seen that under given conditions the expected total costs of service provider operation are minimal when the provider employs five servers.

\section{Discussion and conclusion}

The aging population is currently one of the main issues facing international healthcare systems. A recognized fact is that with advancing age, the rates of developing health problems and chronic disease will increase and the demand for healthcare resources will escalate. Consequently, this will impact the healthcare institutions and LTC facilities (Lovell, 2006). All countries in Europe are experiencing an ageing of their populations, and this trend is projected to continue. This process is often regarded as a primary cause of upward pressure on healthcare costs.

The growth of population aging is also reported for Slovenia. This raises many fundamental questions for policy makers; therefore, much more activity from the state, local communities, relatives and the rest of the social environment is needed. In the ENEPRI research report (Prevolnik Rupel et al., 2010), actions focused on the improvement of elder care system in Slovenia are described. For example, in 2004 different forms of homecare started to

Table 1: Summary of cost optimization of service provider operation

\begin{tabular}{|c|c|c|c|c|c|}
\hline$R$ & $\mathbf{2}$ & $\mathbf{3}$ & $\mathbf{4}$ & $\mathbf{5}$ & $\mathbf{6}$ \\
\hline$E(S C)$ & 13 & 19.5 & 26 & 32.5 & 39 \\
\hline$E\left(N_{q}\right)$ & 9.00 & 6.03 & 3.36 & 1.53 & 0.59 \\
\hline$E(W C)$ & 38.70 & 25.91 & 14.44 & 6.57 & 2.53 \\
\hline$E(T C)$ & $\mathbf{5 1 . 7 0}$ & $\mathbf{4 5 . 4 1}$ & $\mathbf{4 0 . 4 4}$ & $\mathbf{3 9 . 0 7}$ & $\mathbf{4 1 . 5 3}$ \\
\hline
\end{tabular}

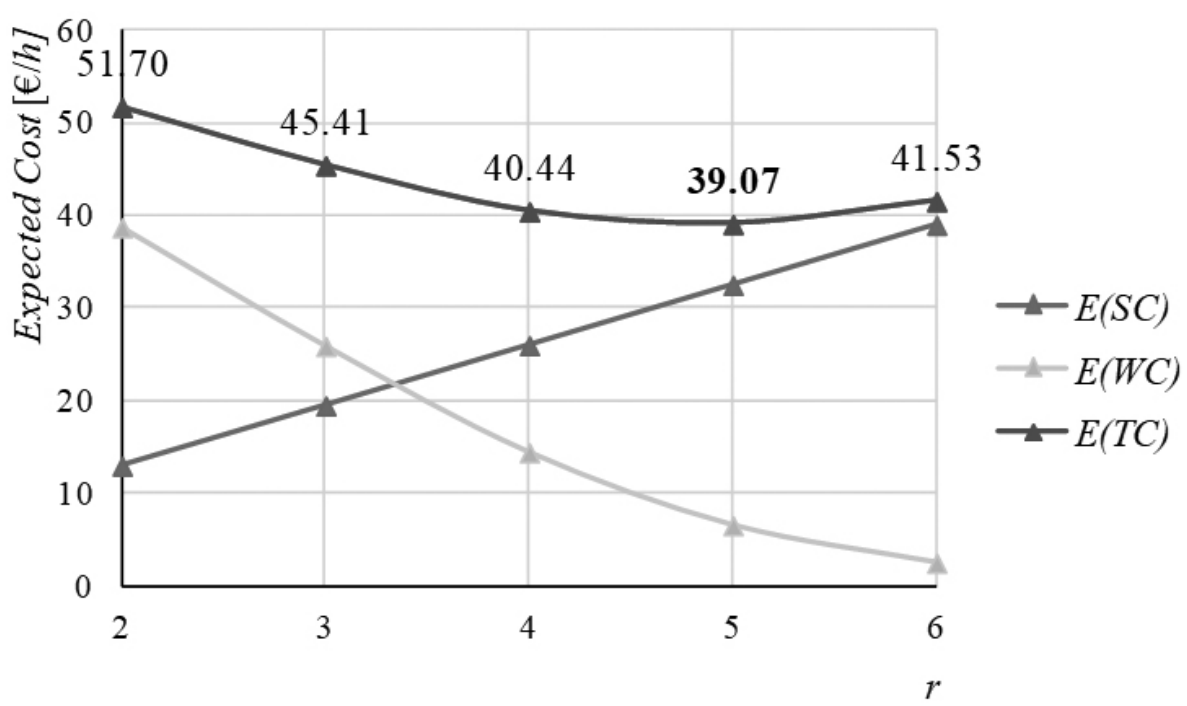

Figure 2: Expected cost of service provider operation 
develop, offered by homes for the elderly, centres for social work, and different voluntary institutions and organizations. Unfortunately, the connection among providers of different kinds of services is weak, which lowers the efficiency of the service. There are also distinct differences in the accessibility of services for persons in the institutional care and persons in homecare as well as high regional differences in the availability of these services. Furthermore, the estimated number of people with severe unmet needs suggests that there are significant opportunities for social policy changes and development of new public and private services for older people in need, as well as for the integration of fragmented LTC (Hlebec, 2016a). These statements confirm the ascertainment that there exists a need for development of additional type of the formal homecare services for the elderly in Slovenia.

In this paper, a new type of formal organizational form of homecare services for elderly people has been examined. All essential characteristics of such an organization, which have to be considered during the establishment of a service provider, have been defined. The focus of our study was oriented towards planning of optimal capacities of personnel team to ensure an appropriate level of service quality. For this purpose, we developed a model based on a queuing theory approach. Using the model, different performance measures of the service provider are calculated. Furthermore, the optimal service capacity is determined, which minimizes the total cost of service provider operation. The usefulness of the model was illustrated by a numerical example. Results obtained proved that such an analysis provides valuable information for decision making, which is valuable, especially in the preliminary phase of service provider establishment. Economic analysis helps the management of service provider to make a trade-off between the increased costs of providing a higher service level and the decreased waiting costs of customers derived from providing that service.

In that development of the model, we identified two important features that we attempted to follow:

- The model should reflect the random nature of elderly (customers) requests as well as random nature of service times.

- The model should be sufficiently simple to be useful in practice.

We found the queueing models to be the natural candidate in view of both features. We note that detailed simulation models may also capture the stochastic nature, but due to the limited availability of data and process information, we opted for simple models that reflect the key characteristics of the elder care delivery process. Such models demonstrate the key principles for supporting staffing decisions on a strategic or tactical level and are sufficiently simple to implement (van Eden et al., 2016).

We assume a simple $\mathrm{M} / \mathrm{M} / \mathrm{r}$ model, which anticipates that both the interarrival and the service times may be well approximated by an exponential distribution. While the assumption of exponentially distributed interarrival times is quite justified, such conclusions for care delivery durations are less affirmative. This is also the main limitation of our study. To prove this assumption, empirical data on the actual care delivery process would be necessary. Moreover, the time needed for the traveling of care workers to customers should also be considered.

In our opinion, the development of a formal homecare service provider network would have many positive effects on society as a whole. First, we expect a great positive impact on the quality of elderly life, especially in the rural areas where a lack of institutional care support exists. Since the idea is based on the market fundamentals, it can represent an opportunity to reduce the existing share of unemployed young people. The idea is also in accordance with Slovenian LTC strategy, which defines that the LTC of the future is to be oriented towards homecare (Prevolnik Rupel et al., 2010).

Despite the fact that long-term elder care will become increasingly necessary in the next decades, the body of operations research (OR) literature directed on this topic remains quite limited (van Eden et al., 2016). We agree with the authors who have challenged the researchers in the field of OR to put more emphasis on research on longterm elder care. They emphasized that finding usable data will be an important first step for future research in this promising field, as reliable and valid information is scarce and seldom collected. Nevertheless, the most important challenge for future research will be to not overemphasize the importance of efficiency because the needs and preferences of the elderly customers should always be kept in mind when researching this area.

\section{Literature}

Aagja, J.P., \& Garg, R. (2010). Measuring perceived service quality for public hospitals (PubHosQual) in the Indian context. International Journal of Pharmaceutical and Healthcare Marketing, 4(1), 60-83, http:// dx.doi.org/10.1108/17506121011036033

Ambler, T. (2003). Marketing and the bootom line: The marketing metrics to pump cash flow. London: FT Prentice Hall.

Babulak, E. (2006). Quality of service provision assessment in the healthcare information and telecommunications infrastructures. International Journal of Medical Informatics, 75, 246-252, http://dx.doi.org/10.1016/j. ijmedinf.2005.07.019

Bashir, B., Chabrol, M. \& Caux, C. (2012). Literature review in home care, 9th International Conference on Modeling, Optimization \& Simulation, Jun 2012, Bordeaux, France. Retrieved July 21, 2017 from https:// hal.archives-ouvertes.fr/hal-00728629/document 
Becker, B., Huselid, M., \& Ulrich, D. (2001). The HR scorecard: linking people, strategy and performance. Cambridge MA: Harvard Business School Press.

Beichelt, F. (2006). Stochastic processess in science, engineering and finance. Boca Raton: Chapmna \& Hall/ CRC.

Bolin, K., Lindgren, B., \& Lundborg, P. (2008). Informal and formal care among single-living elderly in Europe. Health Economics, 17(3), 393-409, http://dx.doi. org $/ 10.1002 /$ hec. 1275

Brezavšček, A., \& Baggia A. (2014). Optimization of a Call Centre Performance Using the Stochastic Queueing Models. Business Systems Research, 5(3), 6-18, http://dx.doi.org/10.2478/bsrj-2014-0016

Camilleri, D., \& O'Callaghan, M. (1998). Comparing public and private hospital care service quality. International Journal of Health Care Quality Assurance, 11(4-5), 127-133, http://dx.doi. org $/ 10.1108 / 09526869810216052$

Cruz-Cunha, M.M., Varajã, J., Miranda, I., Lopes, N., \& Simoes, R. (2012). An e-marketplace of healthcare and social care services: the perceived interest. Procedia Technology, 5, 959-966. http://dx.doi.org/10.1016/j. protcy.2012.09.106

Farris, P. W., Bendle, N. T., Pfeifer, P. E., \& Reibstein, D. J. (2010). Marketing metrics: The definitive guide to measuring marketing performance. Upper Saddle River, NJ: Wharton School Publishing.

Fomundam, S., \& Herrmann, J. (2007). A survey of queuing theory applications in healthcare. The institute for systems research. Retrieved December 17, 2016 from http://drum.lib.umd.edu/handle/1903/7222

Gannon, B., \& Davin, B. (2010). Use of formal and informal care services among older people in Ireland and France. The European Journal of Health Economics, 11(5), 499-511, http://dx.doi.org/10.1007/s10198-010$0247-1$

Genet, N. et al. (2013). Home care across Europe, Case studies, World Health Organization (acting as the host organization for, and secretariat of, the European Observatory on Health Systems and Policies). Retrieved July 21, 2017 from https://www.nivel.nl/sites/default/ files/bestanden/Home-care-across-Europe-case-studies.pdf

Hlebec, V. (2014). Individual and contextual determinants of social homecare usage in Slovenia. Zdravstveno Varstvo, 53(4), 311-317, http://dx.doi.org/10.2478/ sjph-2014-0034

Hlebec, V., Mali, J., \& Filipovič Hrast, M. (2014b). Community care for older people in Slovenia. Anthropological Notebooks, 20 (1), 5-20.

Hlebec, V., Srakar A., \& Majcen B. (2016a). Determinants of unmet needs among Slovenian old population. Zdravstveno Varstvo, 55(1), 78-85, http://dx.doi. org/10.1515/sjph-2016-0011
Hlebec, V., Srakar, A., \& Majcen, B. (2016b). Care for the elderly in Slovenia: A combination of informal and formal care. Revija za Socijalnu Politiku, 23(2), 159-179, http://dx.doi.org/10.3935/rsp.v23i2.1317

Hudoklin Božič, A. (2003). Stohastični procesi [Stochastic Processes], 6th Ed. Kranj: Moderna organizacija.

IFA. (2014). Connecting the dots: Formal and informal care. 2014 Senior Government Officials Meeting $-10^{\text {th }}$ of June 2014, Hyderabad. Received July 21, 2017 from http://www.ifa-fiv.org/wp-content/uploads/2013/08/ Connecting-the-Dots-Formal-and-Informal-Care-Senior-Government-Officials-Meeting-10th-June-2014. pdf.

Kajonius, P.J., \& Kazemi, A. (2016). Structure and process quality as predictors of satisfaction with elderly care. Health and Social Care in the Community, 24(6), 699707, http://dx.doi.org/10.1111/hsc.12230

Kesti, M. (2012). Organization human resources development connection to business performance. Procedia Economics and Finance, 2, 257-264, http://dx.doi. org/10.1016/S2212-5671(12)00086-X

Kotler, P., \& Keller, K. L. (2006). Marketing management, $12^{\text {th }}$ ed., Upper Saddle River, NJ: Pearson Prentice Hall.

Lehmann, D. R. (2004). Metrics for Making Marketing Matter. Journal of Marketing, 68, 73-75, http://dx.doi. org/10.1509/jmkg.68.4.73.42727

Lovell, M. (2006). Caring for the elderly: changing perceptions and attitudes. Journal of Vascular Nursing, 24(1), 22-26, http://dx.doi.org/10.1016/j.jvn.2005.11.001

Lovelock, C., \& Wright, L. (2002). Principles of service marketing and management. New Jersey: Prentice Hall.

Luan, Y. K., \& Sudhir, K. (2010). Forecasting marketing-mix responsiveness for new products. Journal of Marketing Research, 47, 444-457, http://dx.doi. org/10.1509/jmkr.47.3.444

OECD. (2013). Health at a glance 2013: OECD indicators. Retrieved December 17, 2016 from http://www.oecd. org/els/health-systems/Health-at-a-Glance-2013.pdf

Prevolnik Rupel, V., Ogorevc, M., \& Majcen, B. (2010). Long-term care system in Slovenia, ENEPRI research report No. 87. Retrieved December 17, 2016 from http:/www.ancien-longtermcare.eu/sites/default/files/ Slovenia.pdf

Rechel, B., Doyle, Y., Grundy, E., \& McKee, M. (2009). How can health systems respond to population ageing? World Health Organization. Retrieved December 17, 2016 from http://www.euro.who.int/_data/assets/ pdf_file/0004/64966/E92560.pdf

Riedel, M., \& Kraus, M. (2011). The organisation of formal long-term care for the elderly, Results from the 21 European country studies in the ANCIEN project, ENEPRI research report No. 95, 2011. Retrieved December 17, 2016 from http://www.ancien-longter- 
mcare.eu/sites/default/files/RR $\% 20$ No\%2095\%20 ANCIEN_\%20Organisation $\% 20$ of $\% 20$ Formal $\% 2 \overline{0}$ LTC.pdf

Singh, V. (2006). Use of queuing models in health care, University of Wisconsin-Madison. Retrieved December 17, 2016 from https://works.bepress.com/vikas singh/4/download/

Smits, M., \& Janssen, R. (2008). Impact of electronic auctions on health care markets. Electronic Markets, 18(1), 19-29, http://dx.doi.org/10.1080/10196780701797607

Telmo, S., Abreu, J., Antunes, M., Almeida, P., Silva, V., \& Santinha. (2016). G.+TV4E: Interactive television as a support to push information about social services to the elderly. Procedia Computer Science, 100, 580-585.

van Eeden, K., Moeke, D. \& Bekker, R. (2016). Care on demand in nursing homes: a queueing theoretic approach, Health Care Manag Sci, 19(3), 227-240, http:// dx.doi.org/10.1007/s10729-014-9314-y
Polona Šprajc is an Assistant Professor at the Faculty of Organizational Sciences, University of Maribor. Her main research interests are human resource management, marketing and business ethics.

Iztok Podbregar is a Full Professor at the Faculty of Organizational Sciences, University of Maribor. His main research interests concern crisis management, critical infrastructure and human resource management. He is author of several monographs, scientific articles published in Slovenia and abroad.

Alenka Brezavšček is an Associate Professor of Stochastic Processes at the Faculty of Organizational Sciences, University of Maribor. Her main research interests are stochastic processes, system reliability and availability, and information system security. 